\title{
Neonatal Cardiomyopathy and Lactic Acidosis Responsive to Thiamine
}

\author{
H. D. Bakker ${ }^{1}$, H. R. Scholte ${ }^{2}$, I. E. M. Luyt-Houwen ${ }^{2}$, \\ A. H. van Gennip ${ }^{1}$, N. G. G. M. Abeling ${ }^{1}$ and J. LaM ${ }^{1}$ \\ ${ }^{1}$ Emma Kinderziekenhuis, Division of Paediatrics, Academic Medical Centre, \\ Meibergdreef 9, $1105 \mathrm{AZ}$ Amsterdam, The Netherlands \\ ${ }^{2}$ Department of Biochemistry I, Erasmus University, Rotterdam, The Netherlands
}

\begin{abstract}
Summary: A congestive cardiomyopathy was diagnosed in a girl at the age of 4 weeks. In the weeks following she developed general muscle hypotonia and plasma lactate increased to $8.5 \mathrm{mmol} / \mathrm{L}$. Biochemical investigations of a muscle biopsy at the age of 3 months showed a deficiency in the oxidation of all substrates tested: pyruvate plus malate, 2-ketoglutarate and palmitate plus malate. After freezing and thawing of the homogenate and the addition of essential cofactors, the oxidation of the ketoacids normalized. The oxidation defect in the untreated homogenate can be explained by a deficiency in one of the cofactors (such as thiamine pyrophosphate, $\mathrm{NAD}^{+}$or $\mathrm{CoASH}$ ), or by a defect in the oxidative phosphorylation. Treatment with thiamine and carnitine resulted in a decrease in blood lactate to normal levels and a dramatic clinical improvement. Suspension of thiamine caused deterioration of her clinical condition and lactic acidaemia. The thiamine therapy was then continued. The girl is now 6 years old and in perfect health.
\end{abstract}

\section{INTRODUCTION}

Cardiomyopathy is often caused by a metabolic defect (Tripp, 1984; Kohlschütter and Hausdorf, 1986; Lombes et al., 1987; Scholte et al., 1987b; Przyrembel, 1989). Without investigation of the nature of the defect and specific treatment, the prognosis is bad. One-third of the patients die young and half of the survivors are severely handicapped (Tripp, 1984).

\section{CASE REPORT}

M.B., a girl born on 2 March 1984, the first child of unrelated parents, was admitted at the age of 3 weeks because of coughing fits, poor fluid intake, vomiting and loss of weight. Physical examination revealed a greyish skin colour, tachypnea, tachycardy and hepatomegaly. Routine laboratory investigation showed only a mild metabolic acidosis due to elevated plasma lactic acid. At the age of 4 weeks a congestive cardiomyopathy of unknown origin was diagnosed. She was treated with diuretics and lanoxin, and in the weeks following she developed general muscle hypotonia and

MS received 12.12.89 Accepted 25.5.90 
increasing left ventricular hypertrophy and became unable to drink.

A $24 \mathrm{~h}$ urine collected for metabolic investigation revealed no major abnormalities. Plasma lactic acid concentration was also normal at that time. However, in the subsequent weeks plasma lactic acid concentration increased to $8.5 \mathrm{mmol} / \mathrm{L}$. Plasma free and esterified carnitine were in the control range. The excretion of free and esterified carnitine was also normal. After a $16 \mathrm{~h}$ overnight fast the blood glucose concentration was still $4.0 \mathrm{mmol} / \mathrm{L}$. Ratios of free fatty acids $/ \beta$-hydroxybutyric acid, free fatty acids/glucose and $\beta$-hydroxybutyric acid/glucose in plasma were normal. However, plasma lactate rose to $5.8 \mathrm{mmol} / \mathrm{L}$ after $12 \mathrm{~h}$ of fasting and subsequently decreased to $3.5 \mathrm{mmol} / \mathrm{L}$ during the next $4 \mathrm{~h}$ of fasting. A muscle biopsy from the quadriceps was taken under local analgesia at the age of 3 months by Prof. Dr $\mathrm{H}$. F. M. Busch, who found no morphological or histochemical abnormalities. Because of her poor clinical condition and the possibility of a vitamin-responsive metabolic disorder, treatment with L-carnitine $(2 \times 1 \mathrm{~g} /$ day $)$, riboflavin $(2 \times 25 \mathrm{mg} / \mathrm{day})$ and thiamine $(2 \times 25 \mathrm{mg} /$ day $)$ was given in addition to the diuretics and lanoxin while awaiting the results of the biochemical investigations of the muscle biopsy. This resulted in a dramatic improvement both clinically and biochemically. She was now able to drink by herself, the hypotonia disappeared and the blood lactate decreased to normal levels $(1.4 \mathrm{mmol} / \mathrm{L})$. The biochemical investigations of the muscle homogenate revealed a low total carnitine content and decreased oxidation of pyruvate and 2 ketoglutarate, which normalized after freezing and thawing of the homogenate and the addition of the essential cofactors. Treatment with carnitine and thiamine was therefore continued, but riboflavin was stopped. Her clinical condition remained unchanged.

When the girl was 6 months of age we attempted to evaluate the requirement for carnitine or thiamine. For a period of five weeks carnitine was lowered from $2 \mathrm{~g}$ to $0.5 \mathrm{~g} /$ day. It was not completely suspended because of the danger of a temporary carnitine deficiency due to increased carnitine degradation in patients with prolonged carnitine treatment (Scholte and de Jonge, 1985). During a second period of five weeks thiamine was discontinued and the carnitine treatment was maintained. Only during the second period did her condition worsen. The hypotonia gradually reappeared and she again became unable to drink by herself. Blood lactate concentration increased to $4 \mathrm{mmol} / \mathrm{L}$. On reinstitution of the thiamine treatment the clinical symptoms and the lactic acidosis disappeared again.

Now aged 6 years, she is a healthy girl with normal weight and length. Her echocardiogram shows a good contraction pattern and normal wall thickness of the left ventricle. The improvement in the ECG allowed cessation of diuretics at the age of 4 years. X-ray investigation still shows an enlarged heart, but with a normal lung vessel-filling pattern.

\section{METHODS}

Immediately after the biopsy a free homogenate was made consisting of $46 \mathrm{mg}$ muscle in $1 \mathrm{ml}$ of sucrose, heparin, EDTA medium (Bookelman et al., 1978).

The oxidation of $1 \mathrm{mmol} / \mathrm{L}{ }^{14} \mathrm{C}$-pyruvate $+1 \mathrm{mmol} / \mathrm{L} 1$-malate and of $1 \mathrm{mmol} / \mathrm{L}$ ${ }^{14} \mathrm{C}$-2-ketoglutarate was studied in the same medium as that used for the study of 
oxidative phosphorylation (Barth et al., 1983), but at $37^{\circ} \mathrm{C}$, to enable comparison with the results obtained with the frozen muscle.

The oxidation of $\mathrm{U}^{14} \mathrm{C}$ palmitate to ${ }^{14} \mathrm{CO}_{2}$ and ${ }^{14} \mathrm{C}$-intermediates was studied as described by Scholte and colleagues (1987b), and the activity of malonyl-CoA decarboxylase with and without detergent was studied according to the method of Roodhooft and colleagues (1986). A second homogenate was made from frozen muscle ( $28 \mathrm{mg}$ in $0.8 \mathrm{ml}$ sucrose, HEPES, EDTA, albumin medium (Arts et al., 1987)) to study the oxidation of $1 \mathrm{mmol} / \mathrm{L} 1-{ }^{14} \mathrm{C}$-2-ketoglutarate in the presence of thiamine pyrophosphate, $\mathrm{CoASH}, \mathrm{NAD}^{+}$, carnitine, carnitine acetyltransferase and cytochrome $c$. The pyruvate oxidation was studied after $3 \mathrm{~min}$ inactivation by preincubation with $\mathrm{Mg}^{2+}-\mathrm{ATP}$, followed by 5 min activation with $\mathrm{Ca}^{2+}$ and $\mathrm{Mg}^{2+}$ (Arts et al., 1987).

The other assays were performed in frozen batches of the first homogenate as described by Scholte and colleagues (1987a).

\section{RESULTS}

The results of the biochemical investigations of the muscle biopsy are summarized in Table 1. The control data for fresh muscle homogenate were calculated from the data obtained with freshly isolated mitochondria, with the assumption that the theoretical yield of mitochondria is $38 \mathrm{mg}$ of mitochondrial protein per $\mathrm{g}$ of muscle (Scholte et al., 1987a). The control values for $1-{ }^{14} \mathrm{C}$ pyruvate and $1-{ }^{14} \mathrm{C}-2$-ketoglutarate oxidation at $37^{\circ} \mathrm{C}$ were calculated from oxygen uptake rates with freshly isolated mitochondria at $25^{\circ} \mathrm{C}$ (Scholte et al., 1987a), assuming that 5 and 2 ngat oxygen are consumed by the oxidation of $1 \mathrm{nmol}$ pyruvate and 2-ketoglutarate, respectively, and that the oxidation rates at $37^{\circ} \mathrm{C}$ are 2.2 times higher than at $25^{\circ} \mathrm{C}$ (Byrne and Trounce, 1985).

The oxidation of $\mathrm{U}^{14} \mathrm{C}$-palmitate was not measured in frozen-thawed homogenate because, after disruption of the mitochondria, the reaction is no longer linear with respect to time and enzyme concentration. In fresh homogenate the rate of oxidation of pyruvate, 2-ketoglutarate and palmitate was much lower than in controls, while the activity of the mitochondrial marker enzyme malonyl-CoA decarboxylase measured in the presence of detergent was entirely normal. The frozen-thawed homogenate showed normal ketoacid oxidation rates after the addition of the essential cofactors thiamine pyrophosphate, CoASH and NAD ${ }^{+}$.

The activities of the complexes of the mitochondrial respiratory chain, the muscle marker creatine kinase and the protein content were in the control range. Total carnitine was decreased.

\section{DISCUSSION}

Assays were performed in muscle homogenates because the amount of tissue biopsied was too small to allow the isolation of a sufficient amount of mitochondria for reliable functional studies.

In the fresh homogenate, the patient showed a deficiency in the oxidation of all substrates tested: pyruvate, 2-ketoglutarate and palmitate. After freezing and thawing and addition of essential cofactors (thiamine pyrophosphate, $\mathrm{CoASH}, \mathrm{NAD}^{+}$) and 
Table 1 Oxidation of pyruvate and 2-ketoglutarate in fresh and frozen-thawed skeletal muscle homogenate compared with other mitochondrial activities, creatine kinase, protein and carnitine. The data for the patient are of the same muscle, biopsied before treatment. The enzyme activities are expressed as indicated amount of substrate converted $\min ^{-1} \mathrm{~g}$ wet muscle ${ }^{-1}$. The control values for the fresh homogenates were calculated from experiments with freshly isolated mitochondria as indicated in the text. The mean value is given with the range in brackets.

\begin{tabular}{|c|c|c|c|c|}
\hline & Patient & & Controls & $n$ \\
\hline \multicolumn{5}{|l|}{ Fresh homogenates } \\
\hline $1{ }^{14} \mathrm{C}$-pyruvate oxidation (nmol pyruvate) & 88 & \multicolumn{2}{|c|}{$1538(836-2408)$} & 22 \\
\hline $1-{ }^{14} \mathrm{C}-2$-ketoglutarate oxidation (nmol 2-ketoglutarate) & 78 & \multicolumn{2}{|c|}{$2424(1714-2668)$} & 12 \\
\hline \multicolumn{5}{|l|}{$\mathrm{U}-{ }^{14} \mathrm{C}$-palmitate oxidation (nmol palmitate) } \\
\hline$+1 \mathrm{mmol} / \mathrm{L} \mathrm{KCN}+0.1 \mathrm{mmol} / \mathrm{L} \mathrm{CoASH}$ & 1.5 & 8.7 & $(5.7-13.7)$ & 12 \\
\hline$+0.5 \mathrm{mmol} / \mathrm{L}$ L-carnitine $+0.1 \mathrm{mmol} / \mathrm{l} \mathrm{CoASH}$ & 4.4 & 66 & $(42-95)$ & 14 \\
\hline$+5 \mathrm{mmol} / \mathrm{L}$ L-carnitine $+1 \mathrm{mmol} / \mathrm{L} \mathrm{CoASH}$ & 4.5 & 73 & $(43-86)$ & 9 \\
\hline Malonyl-CoA decarboxylase (nmol malonyl-CoA) & 4.7 & 4.9 & $(0.0-31)$ & 9 \\
\hline+ detergent & 38 & 55 & $(33-116)$ & 9 \\
\hline \multicolumn{5}{|l|}{ Frozen-thawed homogenates } \\
\hline $1-{ }^{14} \mathrm{C}$-pyruvate oxidation (nmol pyruvate) & 823 & 866 & $(520-1276)$ & 9 \\
\hline $1{ }^{14} \mathrm{C}-2$-ketoglutarate oxidation (nmol 2-ketoglutarate) & 1169 & 1091 & $(505-2301)$ & 30 \\
\hline Rotenone-sensitive NADH-oxidase ( $\mu$ mol NADH) & 2.2 & 3.2 & $(1.6-4.2)$ & 10 \\
\hline Succinate dehydrogenase $\left(\right.$ nmol $\left.\mathrm{INT}^{+}\right)$ & 563 & 723 & $(187-1640)$ & 58 \\
\hline $\begin{array}{l}\text { Antimycin-sensitive succinate-cytochrome } c \text { reductase } \\
(\mu \text { mol cytochrome } c)\end{array}$ & 2.6 & 4.0 & $(1.6-8.1)$ & 21 \\
\hline Cytochrome $c$ oxidase (rate constant $k$ ) & 57 & 90 & $(45-161)$ & 26 \\
\hline Creatine kinase ( $\mu \mathrm{mol}$ creatine) & 177 & 307 & $(83-430)$ & 50 \\
\hline Protein (mg/g wet weight) & 89 & 174 & $(77-263)$ & 53 \\
\hline Total carnitine $(\mu \mathrm{mol} / \mathrm{g}$ wet weight $)$ & 1.3 & 4.0 & $(2.6-5.7)$ & 59 \\
\hline
\end{tabular}

$n=$ number of controls $\mathrm{INT}^{+}=p$-iodonitrotetrazolium

cytochrome $c$, the activities of the oxoacid dehydrogenases became normal. The apparent deficiency could be caused by a deficiency in one of the cofactors or a defect at the level of thiamine, and because of the carnitine deficiency in oxidative phosphorylation. Other mitochondrial marker enzymes, including segments of the respiratory chain, showed the same activity as in controls. The integrity of the mitochondrial inner membranes, measured by the stimulation of the matrix enzyme malonyl-CoA decarboxylase by detergent, was also normal.

One of the explanations for these findings, a defect at the level of thiamine, and the observed carnitine deficiency, suggested a biochemical basis for a trial of treatment with these substances. The blood lactate normalized within four weeks. The therapeutic regimen appeared to be justified by the dramatic improvement in the patient's condition and the disappearance of the lactic acidosis. The early onset of the disease, and the fact that lactic acidosis reappeared after suspension of the treatment, excludes beriberi and we therefore suspect that the patient has a defective incorporation of thiamine. The carnitine deficiency in the muscle is likely to be a consequence of the defect in the Krebs cycle. Acetyl-CoA is no longer oxidized and one would expect increased acetylcarnitine to be excreted with the urine, resulting in depletion of tissue carnitine. The normal level of urinary acetylcarnitine could support this theory, in 
view of the much lower muscle carnitine pool in the patient. The reduced beta oxidation in the muscle homogenate also remains to be explained. Since it is measured in the presence of the required factors, including L-malate, the decrease cannot be caused by the defect in 2-ketoglutarate oxidation. The decrease in mitochondrial and peroxisomal (measured in the presence of $\mathrm{KCN}$ ) palmitate oxidation is probably caused by dilution of the labelled palmitate by long-chain fatty acids, released from the triacylglycerols by lipoprotein lipase, stimulated by heparin, which was present in the homogenization medium.

Although the precise metabolic defect has still to be assessed, we conclude that our patient has a defect in thiamine metabolism which is responsive to thiamine. This implies that carnitine can be tapered off without clinical consequences. We advocate metabolic investigation of patients with cardiomyopathy, followed by rational treatment based on the biochemical lesion(s) encountered in skeletal muscle biopsy.

\section{REFERENCES}

Arts, W. F. M., Scholte, H. R., Loonen, M. C. B., Przyrembel, H., Fernandes, J., Trijbels, J. M. F. and Luyt-Houwen, I. E. M. Cytochrome $c$ oxidase deficiency in subacute necrotizing encephalomyelopathy. J. Neurol. Sci. 77 (1987) 103-115

Barth, P. G., Scholte, H. R., Berden, J. A., van der Klei-van Moorsel, J. M., Luyt-Houwen, I. E. M., van't Veer-Korthof, E. T., van der Harten, J. J. and Sobotka-Plojhar, M. A. An Xlinked mitochondrial disease affecting cardiac muscle, skeletal muscle and neutrophil leucocytes. J. Neurol. Sci. 62 (1983) 327-355

Bookelman, H., Trijbels, J. M. F., Sengers, R. C. A. and Janssen, A. J. M. Measurement of cytochromes in human skeletal muscle mitochondria isolated from fresh and frozen stored muscle specimens. Biochem. Med. 19 (1978) 366-373

Byrne, E. and Trounce, I. Oxygen electrode studies with human skeletal muscle mitochondria in vitro. J. Neurol. Sci. 69 (1985) 319-333

Kohlschütter, A. and Hausdorf, G. Primary (genetic) cardiomyopathies in infancy. A survey of possible disorders and guidelines for diagnosis. Eur. J. Pediatr. 145 (1986) 454-459

Lombes, A., Hervé, F., Ogier, H., Pellet, A., Sidi, D., Villain, E., Kachaner, J., Charpentier, C., Paturneau-Jouas, M., Fardeau, M. and Saudubray, J. M. Myocardiopathies primitives d'apparence idiopathique, chez l'enfant. Place des étiologies métaboliques. Arch. Fr. Pediatr. 44 (1987) 569-578

Przyrembel, H. Erkrankungen des Herzens durch Stoffwechseldefekte. Wiener Klin. Wschr. $101(1989) 1-8$

Roofhooft, A. M., van Acker, K. J., Martin, J. J., Ceuterick, C., Scholte, H. R. and LuytHouwen, I. E. M., Benign mitochondrial myopathy with deficiency of NADH-CoQ reductase and cytochrome $c$ oxidase. Neuropediatr. 17 (1986) 221-226

Scholte, H. R. and De Jonge, P. C. Metabolism, function and transport of carnitine in health and disease. In: Gitzelmann, R., Baerlocher, K. and Steinmann, B. (eds.), Carnitine in der Medizin, Schattauer, Stuttgart, 1985, pp. 21-59

Scholte, H. R., Busch, H. F. M., Luyt-Houwen, I. E. M., Vaandrager-Verduin, M. H. M., Przyrembel, H. and Arts, W. F. M. Defects in oxidative phosphorylation. Biochemical investigations in skeletal muscle and expression of the lesion in other cells. J. Inher. Metab. Dis. 10 Suppl. 1 (1987a) $81-97$

Scholte, H. R., Luyt-Houwen, I. E. M. and Vaandrager-Verduin, M. H. M. The role of the carnitine system in myocardial fatty acid oxidation: carnitine deficiency, failing mitochondria and cardiomyopathy. Basic Res. Cardiol. 82 Suppl. 1 (1987b) 63-73

Tripp, M. E. Congestive cardiomyopathy of childhood. Adv. Pediatr. 31 (1984) 179-206 